\title{
Developing Social Alongside Technical Infrastructure: A Case Study Applying ICTD Tenets to Marginalized Communities in the United States
}

Leah Anne Teeters
Vanderbilt University Medical Center, USA

Corresponding Author.

leah.Teeters@,vanderbilt.edu

This article provides a model by which to apply ICTD tenets within the context of the U.S. It presents a case study of co-designing a technology application with community health workers, promotoras, working in a historically marginalized community within the U.S. It examines both the process of co-design as well as the use of the designed product as interventions intended to enhance the promotoras' agency and ability to transform opportunities for themselves and their community. This article argues that designing equity-oriented design solutions involves ethnography and participatory design, as well as attention to both the social and technical infrastructure.

\section{Introduction}

New information and communication technologies (ICTs) have been positioned as an integral part of development (e.g., Friedman, 2006; Greenberg, 2005; Roy, 2005). Although research in ICT has extensively developed tenets for information communication technologies for development (ICTD), there has been little research that has applied these principles within marginalized communities in developed countries.

Teeters, L.A. (2017). Developing social alongside technical infrastructure: a case study applying ICTD tenets to marginalized communities in the United States. The Journal of Community Informatics, 13(1), 193-209.

Date submitted: 2016-04-13. Date accepted: 2016-12-04.

Copyright (C), 2017 (the authors as stated). Licensed under the Creative Commons AttributionNonCommercial-ShareAlike 2.5. Available at: www.ci-journal.net/index.php/ciej/article/view/1311 
This article uses a case study developed from a longitudinal design and ethnographic research study conducted with a marginalized community in an urban city in the United States to illustrate how ICTD principles can help empower people to improve their own communities.

Our work has employed ethnographic research as a foundational method to generate innovative and empowering technology designs. Our research has been oriented around the process of organizing opportunities for enhancing professional practices and promoting equity with a group of resident-activists seeking social justice for their historically marginalized community, South Elm. ${ }^{1}$ South Elm's affordable rental market and close proximity to the city's downtown has historically attracted a significant immigrant population. 2014 Census data reports that $80.7 \%$ of the population is originally from Mexico. Recently, public officials and local non-profits have been directing financial and intellectual resources into developing the community. However, historically South Elm has been under-resourced, making it challenging to develop competitive schools, neighborhood parks, bike lanes, and community centers. The rates of formal education and stable employment are low while the rates of unemployment, drug abuse, and poverty are high. Additionally, there are limited grocery stores, classifying the neighborhood as a food desert, meaning that there is limited access to fresh, affordable food. As part of the effort to provide improved infrastructure to South Elm, a local non-profit, Impact, is working to improve the residents' access to healthy, affordable food. Impact, established in 2007, has developed a community-based agriculture program, a community-supported agriculture-buying club, and a resident owned co-operative market.

Impact's mission is to support community leaders, generate local food systems, and cultivate self-sufficient economies. A key component of Impact's approach is their promotora model. The model was developed to leverage the shared cultural traditions, linguistic practices, and value systems between community members and the promotoras (Siraj, Shabham, Jalal, Zongrone, \& Afsana, 2010). Impact's promotoras support community members in designing, installing, tending, and harvesting their own backyard vegetable gardens. In 2015, Impact's backyard gardens produced more than 54,400 pounds of fruits and vegetables. The neighborhood now has 400 gardens and a waitlist with over 100 residents who want an Impact garden, which includes an irrigation system, seeds, seedlings, and the support of a promotora throughout the growing and harvesting season.

In addition to this highly visible work in the neighborhood, the promotoras also serve, unofficially, as advocates for residents. Through the process of working across hundreds of backyard gardens, the promotoras have learned about the challenges of the neighborhood's residents: access to health care, education, legal services, and concerns with addressing and preventing violence against women. The promotoras heard these challenges as a call to action and began organizing as advocates, connecting community members to resources and writing grants to further support their work. 
The intensive work of maintaining thriving gardens and the extensive work of community advocacy had not been fully documented as part of Impact's data collection efforts prior to the initiation of the research described below. This made it difficult to specify programming needs, to report on the effectiveness of the model, and to understand areas for growth. The promotoras expressed desires to enhance their professional abilities as gardeners, as non-profit employees, and as community advocates. In order to secure funding for professional development resources and to know which skills to best target, there was a need to more fully document their practices, streamline data collection, and enhance technological capacity.

The aim of our research team has been to support the non-profit in developing strategies to enhance learning and professional practices oriented at improving their work in the community. This article focuses on one of our co-designed interventions: a technology application that allowed the promotoras to collect systematic data. It examines both the process of co-design as well as the use of the designed product, exemplifying the process of (a) using ethnographic work to situate the design process within the ecosystem, (b) attending to the social and technical infrastructure, and (c) using ICTD principles within a marginalized community within a developed nation.

\section{Beyond access and toward equity}

In an era where technological access is seen as a fundamental freedom and an imperative to development (e.g. Oppenneer, 2009; Sachs, 2005), there is a need to push beyond questions of access to consider questions of equity. Equitable technology development entails developing tools that reflect the values and knowledges of diverse people and open up new and valued opportunities for users. Although technology has the potential to provide access to education, healthcare, financial tools, and improve existing practices, it can also serve to reinforce existing inequalities (Kleine, 2012). As Toyama (2010) argues, "technology - no matter how well designed - is only a magnifier of human intent and capacity. It is not a substitute" (italics in original, p. 15). Focusing solely on access to technology risks deflecting attention from the underlying economic and social structures of inequity. There is therefore a need to further develop strategies of technology development that foreground equity and attend to the social infrastructure in addition to the technical infrastructure.

Situating technology development within the ecosystem where it is intended to be used can orient designs towards greater equity and sustainability. Digital Green, an organization that develops technologies to improve agriculture, health and nutrition, suggests some principles to develop technologies that can enhance the skills of local community members: (a) a participatory process for content production; (b) a locally generated video database of videos on agricultural practices; (c) human mediated instruction for dissemination and training; and, (d) structured sequencing to initiate new communities into Digital Green's community of practice (Gandhia, Veeraraghavan, Toyama, \& Ramprasad, 2007). Similarly, Groupe Speciale Mobile Association's (GSMA) Mobile for Development's agricultural program (mAgri), employs usercentered design to understand the ecosystem of the users. This program works with mobile operators and local communities to enhance the capacity of smallholder farmers 
by improving access to information, financial services and supply chain solutions (mAgri, 2016). By situating their work within the local ecosystem, design solutions can attend to the needs, challenges, constraints, and desires of the users, resulting in transformative practices (Palmer \& Pshenichnaya, 2015). Digital Green and mAgri are two examples of technologies that were developed alongside human abilities and have effectively served as tools that 'magnify' human capabilities (Tomaya, 2010).

The case analysis presented in this article looks at how ethnographic work can inform participatory design to improve the social and technical infrastructure, providing users with an enhanced capacity to shape their own professional practices. To measure the enhanced ability to shape professional practices, the analysis presented in this article examines how technology has supported the users in representing their own practices and how it has increased their ability to transform their own work in the community.

\section{Research context and design}

\section{Background of collaboration and initial data collection}

The work of designing a technology application emerged from our long-term participatory research project organized around the design of participant structures, knowledge trajectories, and technical tools that could enhance Impact's approach to food justice and community advocacy (Jurow, Teeters, Shea, \& Van Steenis, 2016). Our partnership with Impact and the promotoras began in 2012 when we were invited into the organization to help Impact better articulate the promotora model and enhance their practices so that it could be replicated elsewhere. Our first year of partnership consisted of ethnographic work aimed at understanding the promotoras' professional practices, including their strengths, desires, and challenges. We interviewed promotoras and the Impact directors, reviewed historical and contemporary artifacts on the promotora model, and engaged in participant observations of the promotoras' and Impact's work in the community.

In collaboration with the promotoras and Impact directors, we then organized for a series of professional development workshops aimed at articulating and enhancing the promotoras' work with each other and community members. We documented the coplanning process, the workshop implementation, and post-workshop reflections with videotapes, fieldnotes, audio recordings, and artifact collection.

Our data collection and analysis proceeded simultaneously so that each could inform the other (Strauss, 1987). The analysis of our ethnographic data and workshop data drew attention to key themes, indicating an interest in further professional development, a desire for greater awareness of the layers of the promotoras' work, and a need for more streamlined data collection. To address these needs, 20 months after we began our collaboration with Impact, we commenced the process of co-designing a technology solution that could support the promotoras in designing surveys that would allow them to collect, aggregate, and analyze data on what they believed was most essential in regards to their work in the community. 


\section{Data collection on ICT development and implementation}

Our team documented our participatory design process of developing a software application (called the "Promotora App") using audio and video recordings as well as fieldnotes. We shadowed the promotoras in the field prior to observe their methods of data collection. We did this prior to developing the Promotora App and throughout the multiple iterations to developing and implementing the Promotora App. We conducted informal interviews focused on the promotoras' experience using the Promotora App and on Impact's staff's and co-directors' experience using its data.

It is important to note that in addition to interviews, observations, artifact analysis, and documentation of our collaborative workshops and technology design sessions, much of the material that has contributed to our analysis emerged from confidential conversations. We learned about the promotoras' challenges and successes while driving to gardens, sharing meals, attending community events, and shadowing the promotoras in the gardens. These informal meetings allowed us to understand what mattered to the participants and what new infrastructure would be valued. This cultivation of trust allowed for participants to share more contentious and politicized experiences and concerns and is integral to the design of equitable and sustainable interventions (Delgado-Gaitan 2005; Foley \& Valenzuela 2005). We have protected the personally revealing stories shared with us by keeping all data collected confidential, receiving permission for the data pieces that we do use, and soliciting feedback on our research findings.

\section{Analytic approach}

Throughout our collaboration, data collection, technology design, and analysis have been iteratively employed, so that each process could be informed by a systematic review of data, as related to the literature (Glaser \& Strauss, 1967). In addition to the iterative nature of data collection and analysis, triangulation was used to ensure rigor (Denzin, 1989). The study triangulated methods, using diverse forms of data collection (e.g. interview, participant observation, video analysis), and triangulated sources, collecting data from different stakeholders (e.g. the promotoras, the technologists, the co-directors, office staff, community members).

The case study presented in this article was developed from a review of data sources on the initial impetus for the design work and on the process of co-designing the Promotora App. Data were analyzed with specific attention given to participation and the execution of agency. The analysis aims to understand how the process of co-design and the use of the new tool affected the social organization of the promotoras' work, its representation within Impact, and its durability as a practice that could be reflected upon and revised over time.

Analysis was informed by the Choice Framework (Kleine, 2013). The Choice Framework (a) values holistic measures - including measures of well-being, as defined by individuals - as opposed to econocentric measures, (b) is systemic as opposed to linear, (c) is user-centered as opposed to top-down, and (d) is choice-led as opposed to 
supply-led. This framework encourages the assessment of social structures, agency, and dimensions of choice, or what Alsop and Heinsohn (2005) refer to as degrees of empowerment.

\section{Case study findings}

\section{Understanding the social infrastructure}

Developing a tablet based application was one of the interventions that we co-designed with Impact to support the co-directors and the promotoras in enhancing their understanding of each other's work and to support the promotoras in improving their professional repertoires. Before articulating a focal problem or a design solution, we engaged in a year of ethnographic research that consisted of research within the organization, the community, and the city. We sought to locate Impact's work across multiple scales of participation and from multiple perspectives. This broad view provided us with a deep understanding of the promotoras' expansive activity system (Jurow \& Shea, 2015).

\section{Identifying gaps between the social and technical infrastructure}

In an effort to generate reflective spaces where the promotoras could articulate their work and generate visions for their collective future, we organized a series of three workshops that took place over three months. Through mediated dialogue, reflective writing, guided teatro ${ }^{2}$, and the creation of representational artifacts, the promotoras were able to generate shared desires, visions, and frustrations. During the course of the workshops, the promotoras had the opportunity to articulate the extensiveness of their practice, which included not only gardening tasks such as clearing plots, rototilling, planting seeds, troubleshooting infestations, and harvesting plants but also community networking efforts. The promotoras expressed that they took great pride in their work and desired more tools and resources to enhance their practices.

As we documented the layers of the promotoras' work, noting that it was not fully visible to the non-profit leadership, we also heard frustrations with current methods of data collection. In the years prior to the development of the app, the promotoras went from house to house, conducting surveys with pen and paper to gather feedback on the community's attitudes towards the backyard garden initiative and to evaluate desires for other initiatives, such as community classes. These surveys were later entered into a computer-based database. Not only was this method inefficient, but the information was difficult to gather due to language and literacy issues. As the lead promotora shared:

Yo pienso que un obstáculo es que la gente no tiene educación. La gente no sabe leer y escribir. Así que, cuando hago una encuesta, es difícil.

One obstacle that I think is that people do not know how to read and write. So, when I do a survey, it is hard. (Meeting Transcript, Verónica, 12/14/12). 
The promotoras circulate the neighborhood, asking residents to provide feedback on the promotoras' work, but at times, residents did not have the literacy skills to complete the language-dense survey, and thus the promotoras had to read the survey to the residents, asking them questions, such as, "How well did your promotora meet your needs?" Having the promotoras collect data on their own practices resulted in potentially inaccurate results. Furthermore, collecting the data with pen and paper, later to be transcribed into a computer database, was inefficient.

Moreover, the organization was collecting data on pounds of vegetables harvested, health of the gardens, and satisfaction of community participants, but was not capturing the day-to-day tasks that made these results possible. As a result, describing the specifics of their work had been difficult. As one promotora shared:

Lo que nos falta es saber que somos un equipo. Estamos en el mismo lado. Trabajamos juntos por la misma organización.

What we are missing is to learn that we are a team. We are on the same side. We work together for the same organization. (Meeting Transcript, Maria, 2/11/2013)

The promotoras struggled to articulate their work not only among each other but also within the organization.

The difficulty of describing and supporting the robustness of the promotoras' work, at the start of our research with Impact, was further compounded by the division of tasks within the organization: the promotoras conducted the work of growing and maintaining the gardens and establishing community relationships while the co-directors and a small team of office staff engaged in the work of securing grants, networking with city officials, and marketing the organization. This division of labor, in addition to incomplete documentation of the fullness of the promotoras' work, resulted in different understandings between the office staff and the promotoras regarding existing practices and visions for how to improve the organization. In a whole group meeting, the lead promotora asked that the co-directors become more involved in the community:

A mi me gustaría mucho que Impact, o sea [names co-directors], hmmph, se involucran más con las necesidades de la comunidad. Que ellos aprenderán a conocer las necesidades más. No, no más de la alimentación porque en la comunidad hay necesidades al respecto de la salud respeto a la educación...

I would like very much that Impact, namely [names co-directors], hmmph, become more involved in the needs of the community. That they will learn to know the needs more. Not only about the nutrition because in the community there are needs with respect to health, with respect to education... (Workshop Transcript, Verónica, 5/6/2013)

This request that the co-directors better know the needs of the community demonstrates that the promotoras knew that improving their work would require the co-directors to understand the needs that they encountered when they went out in the community. More 
fully documenting the promotoras' practices and streamlining data collection would allow for the organization to secure funding for professional development resources and to know which skills to best target for training. Moreover, greater visibility of the promotoras' practices could result in more informed programming decisions and an enhanced ability for the organization to meet the needs of the community.

Analysis of multiple data sources, including video recorded workshops, audio recorded meetings, audio recorded interviews, and fieldnotes of participant observations indicated a need for an intervention that could support the promotoras to: 1) enhance the professionalism of their practice, 2) make the extensiveness of their work more visible, 3) share and expand their knowledge, and 4) provide them greater access to resources. Through conversations with technology experts, the promotoras, and Impact leadership, we decided upon building a software application using open source data collection tools (Brunette et al., 2013).

We aimed to generate a software application that could serve the function of a manual, but that would also allow for iteration, capturing the dynamic nature of the promotoras' practice. This appealed to the non-profit leadership due to the potential to "track key metrics and progress" so as to better report on and improve its work in the South Elm community (email exchange between research partners and Impact director, August 9, 2013). The idea appealed to the promotoras as a tool to better represent their work, increase communication with each other and with the non-profit leadership, and allow for enhanced access to resources to improve their practices. A tablet-based application could address the organization's needs by (a) supporting the promotoras to enhance their technological skills, (b) allowing for them to gain greater professional recognition, (c) connecting them to other professional networks, and (d) providing Impact with targeted data.

\section{Coordinating social and technical development}

In order to develop a software application, we collaborated with faculty and Masters of Science students in the College of Engineering at our university. This partnership brought together professionals with diverse backgrounds and forms of expertise. The promotoras brought their expertise in gardening, community building, and Spanish language communication. The three technologists with whom we partnered brought their expertise in technology design and implementation. They are male, native to the U.S. and native English speakers. The education researchers, which included the project P.I. and myself, brought expertise in ethnographic research and designing learning environments. We are both female, and native English speakers with Spanish language abilities. The success of our partnership was reliant on the diverse expertise and diverse backgrounds of each group.

Developing a software application that would truly support the promotoras in enhancing their professional practices required explicit consideration of how to honor the diverse knowledges present amongst our team, intentionally planning opportunities for equitable engagement throughout the design process. As we quickly learned, equitable participation in the design process did not mean equal participation at every stage. In 
one of our very early meetings, we recognized that we would have to design our collaborative meetings with specific attention to language, gender, and culture. This became apparent in a meeting with the English-speaking, male technologists, the bilingual male co-director, the Spanish-speaking, female promotora (who is developing her English proficiency), and myself, a bilingual education specialist. I was positioned as the translator, yet, as the conversation became increasingly technical, the promotora, Verónica, struggled to follow the conversation. I similarly struggled to find the highly technical language required to translate the technologists' terminology. Therefore, although Verónica had significant expertise regarding the intended use of the technology, as the meeting moved along in quick, technical English, Verónica leaned over and whispered to me "me da sueno" (this makes me sleepy), illustrating the extent to which she was disengaged with the design process when we met as a whole group (Meeting Transcript, Verónica, 12/2/2013). In another meeting where we gathered as a full group, the technologists discussed how to create the forms for the application in an Excel spreadsheet before uploading the information to the application. It was not until after the whole team meeting, when I met one-on-one with Verónica, that she shared that she did not have experience with Excel.

These two examples illustrate how, when we privileged the technical demands over the social organization, the process resulted in the disengagement of the promotoras. Analyzing these meetings allowed us to identify, and attend to, the inequitable structures of participation. Moving forward, we re-organized the collaborative process so as to better mediate the collaboration. I led the effort to meet with the technology students so they could share their expert knowledge of technological platforms with us. This knowledge was then brokered in smaller meetings with the promotoras, where I could individually learn about their existing experiences with technology, support them to develop necessary skills, and broker knowledge specific to the emerging technology design.

As we shared the features of the suggested platforms with the promotoras, the promotoras then shared their expertise of the content that would populate the application, enabling everyone to imagine how the application would best be implemented. In this way, our collaboration developed boundary practices, where we generated hybrid practices from both research and practice (Akkerman \& Bakker, 2011). As we integrated these boundary practices into routine work, we opened up opportunities for new, and potentially transformational, learning and systems of organization.

In these more intimate settings, the promotoras made suggestions, such as generating interactive forums that could support sharing gardening problems and solutions among promotoras, and they modified the content, such as better aligning the questions in the different forms to mirror the growing season. Meeting in smaller groups was important to our participatory design work because it allowed us to share our mutual forms of expertise.

As the work progressed, we eventually began meeting as an interdisciplinary team again, but with just one representative from each specialty area. In these smaller 
meetings we organized for different people to lead various stages of the collaboration. For example, in developing a requirements document, the promotoras shared their vision for how it would be used and the technologists created a document describing what that would mean for technical requirements. They detailed: (1) Ease of Use: a) monolingual with an ability to change language; b) simple graphical user interface (GUI); c) automatic WIFI synchronization; d) standalone platform; and, (2) Power of Data a) pre-populated answers for common reporting variables; b) pictures c) secure; d) compatible with existing infrastructure; f) easily learned (Viggio, Dudley, \& Buckner, 2013). The co-director, the lead promotora, and the technologists collaboratively selected a platform from the options identified by the technologists. The team decided upon using a platform developed via Open Data Kit (ODK) called Formhub.

Formhub was created by the Columbia University Sustainable Engineering Lab to aide in small-scale offline data collection. It uses ODK applications to interact with the data collected, sending it to a Formhub server, which aggregates the data into readable outputs (Pokharel, et al., 2014). The technologists led the work of selecting a platform that would meet the promotoras' needs. Then, upon deciding on this software, the promotoras led the process of developing the content of the 'Promotora App.'

This collaborative, interdisciplinary design process positioned the promotoras as designers, apprenticing them into the practice using tablet-based applications to collect data on their work (Lave \& Wenger, 1991). This model allowed for the promotoras to acquire the skills necessary to contribute to the design of technology, as opposed to simply being the recipients of a designed intervention. This deeply participatory approach aimed to mitigate the risk that our design solutions could further marginalize non-dominant participants (Kleine, 2013). In this way, the process of co-design was as much a tool for empowerment as the actual technology.

\section{Implementation and iteration of new infrastructure}

Upon completing the design of the technology platform, we organized a series of handson trainings for all of the promotoras. The lead promotora, Verónica, led these sessions. In preparation, the education team met with Verónica and one technologist to make sure that she was comfortable guiding the promotoras through setting up the hardware and software. Together we developed a presentation that would lead the group of promotoras through the process of taking the tablets from the box and setting them up, downloading the required software, accessing the forms that Verónica had created, and moving through the process of how they would use the application to input information and take pictures while in the garden. Verónica carefully tried to anticipate questions or confusions that the promotoras might have. For example, she included instructions on how to power on the tablet, noting that the Android tablets' basic features were different than the promotoras' smartphones, which were mostly iOS.

This training took place in the winter, a few weeks before the promotoras planned to enroll families in the backyard garden program. A week after the promotoras began using the application to enroll residents and collect household demographic information, Verónica sent me an email in which she wrote: 
Pues ya empezamos desde la semana pasada, parece que todo va funcionando bien, ( I hope ), Yo no ando haciendo aplicaciones, andan algunas de las promotoras y promotor.

Well, we already started last week, and it appears that all is working well (I hope), I have not been going to do the applications, some of the promotoras and the promotore are going. (Email, Verónica, 1/22/2014).

Of note in this exchange is that shortly after being trained on using the new technology, the promotoras were successfully using it to make their work of filling out resident applications easier. They were able to input the information directly into the software, as opposed to gathering it and then later inputting it into their database. The enhanced efficiency allowed the lead promotora to stay in the office, analyzing data so as to immediately inform next practices.

However, the initial report that "all is working well," did not last through the gardening season. By mid-summer, the lead promotora shared this list of complications with me in an email:

1) Muchas veces cuando quiere enviar una forma sale que es error y no se manda.

(Often when we want to send a form it comes up as an error and it won't send.)

2) A veces cuando se va a tomar la foto se apaga.

(Sometimes when we take a photo it turns off.)

3) En ocasiones se batalla para bajar las aplicaciones.

(Sometimes we struggle to download applications.)

4) Eso es lo que pasa mas en las tabletas y nosotros en la oficina muy seguido tenemos problemas para tener acceso a form hub, y es muy frustran.

(This is what occurs most frequently in the tablets and in in the office we also have problems accessing formhub and this is very frustrating.)

(Email, Verónica, 7/10/14)

As I began troubleshooting these glitches with the promotoras, the Impact leadership was simultaneously expanding their vision for their technological needs. The platform that we were using for the Promotora App was not compatible with the software that the organization was considering adopting to support their grant writing, financial management, and needs assessment of the neighborhood. In seeking both a solution to the promotoras' frustrations and the organization's expanding technical needs, the team found that Formyoula (C) best met the non-profit's low cost and offline requirements. We therefore started the process of moving the data system over to the new platform. 
A few months into using the new platform, we learned that elements of the software that the technologists and I assumed to be intuitive were not so for the promotoras. The codirector sent one of the technologists, John, and me an email reading:

So the promotoras are all filling out forms on the tablets, but they are not sending into Formyoula - there are only ten responses showing in total in Formyoula and I can't figure out how to get a view that shows responses per form, etc... can you help us? Thanks! (Email, Matt, 1/28/2015)

John used his tablet and phone to test the software, and when he tried it, the problem described in the email was not present. Not being able to understand the promotoras' difficulties via email, John and I set up a time to meet with a group of 5 of the promotoras.

When observing, in person, the promotoras' use the application, we were able to understand that we had made assumptions about how the promotoras would use the software. This fieldnote excerpt details the process of understanding why the backend database was not showing the completed forms:

Verónica logs into the website on her computer. She points to the 10 'recent' forms on the dashboard, saying that is all that is showing up. Anna (another promotora) and Verónica are both saying, 'where do they go?' 'where are they?'

John then goes to each form, and shows how the individual forms have a selection action button, where you can see all of the forms. Verónica had not been using this. (problem \#1, solved) Nonetheless, the promotoras have done around 90 applications and only 9 new participants and 29 returning participants are showing up.

We get into the tablets and, looking at Anna's, there are a lot of forms listed, but next to them there is a grey icon reading 'draft.' The forms had never been submitted, just saved.

Jocelyn (another promotora) has not yet done any applications. The other tablets though, also look the same, with the forms showing draft. The forms have not been submitted.

John shows how to submit the forms. When he does so, they show up in the database.

Verónica then explains that she doesn't press submit because then she can't start a new application and when she is out in the neighborhood, she often has to fill out 10 applications before she can logon to internet to 'send' them. John is confused by this and so he tests it by turning off the wifi on the tablet and then trying. He is able to submit it (it saves, then showing the logo: 'local,' which means that it is submitted but offline, so when it syncs, it will be uploaded) and then open up a new form. Verónica shares that she assumed that she shouldn't submit, but didn't try it. (Fieldnote, $1 / 29 / 2015)$ 
In designing technology with users, you can anticipate needs, but you can't anticipate how that will be taken up. This example illustrates how we could not have foreseen that the promotoras would 'save' rather than 'submit.' When we were troubleshooting via email, we could not have imagined the root cause for the forms not being uploaded. Understanding what was going on required that we observe how the promotoras were using the software. After this initial glitch, the promotoras took on greater responsibility for using both the application and the tablets. They since have reported using the tablets: "Cada vez que van a un jardín, todos los días" (Every time that they are in a garden, all of the days) (Email, Verónica, 511/2015).

\section{Sustaining social and technical changes}

Using the tablet-based application streamlined the promotoras' data collection, facilitating their daily work. The lead promotora shared:

Les gusta mucho porque les facilita mucho el trabajo y no tienen que traer tantos papeles.

They like [the app] a lot because it supports their work and they don't have to carry so many papers. (Email, Verónica, 5/13/2015)

Not only has the Promotora App enhanced the promotoras' work and facilitated data collection, it has also encouraged the promotoras to explore new ways to use different features of the tablet. They use the tablets to communicate amongst each other, sending emails, sharing photos, and coordinating calendars. As the lead promotora wrote of the whole team: "estan mas comunicados entre si" " (they are in more communication with each other) (Email, Verónica, 5/13/2015). They also use them to record their daily activity, logging garden tasks, recording details about the families, tracking how produce is used, delineating next steps in the garden, and detailing their work that extends beyond the task of gardening.

The promotoras also integrated the use of the tablets into their daily lives. Several promotoras shared that their comfort using the tablet has increased through routine use of it in their work in the gardens. As a result, they were now using the tablet to check their children's school's website and do online banking. Verónica shared that the promotoras use the tablets:

para jugar, jajaja, no aparte de eso para sus e-mail, para su calendario, creo que ya es parte de su vida diaria

to play, hahah, no, aside from this, for their emails, for their calendars, and I believe that they are a part of their daily life. (Email, Verónica, 5/13/2015)

Additionally, the promotoras reported that they shared the tablet with their family members. One promotora reported that her son uses it to play games and took on the responsibility of updating the operating systems and applications. 
The promotoras' work has become more fully visible as all of the promotoras use the Promotora App to codify their practices. As a member of the office staff reported, the practice of systematically documenting their work via technology allowed for "amazing data collection" (Email, Caroline, 5/18/2015). The more systematic, streamlined data collection has enabled the organization to more fully report and solicit funding for the promotoras' work, including elements of their advocacy and community building work. Moreover, the increased visibility of their work has allowed for the promotoras and the non-profit co-founders to provide each other with more specific, and timely, feedback on their work and in turn allows them to improve their skills and supports the non-profit to more effectively achieve its goals of promoting food justice.

The Promotora App has increased communication between members of the organization and has brought the promotoras' work into the office in a more visible way. The promotoras are now charged with the technical work of documenting and analyzing their own practices. The lead promotora took on the responsibility of generating the forms for the Promotora App. With this technical responsibility also came the request for a laptop computer and a transition from being paid hourly to being on a salary. The co-directors responded to Veronica's shifting role, acknowledging the need for resources and appropriate compensation to accompany her shifting responsibilities. Similarly, Impact reorganized the structure of the roles within the organization to adopt a distributed model of leadership, where promotoras share roles and responsibilities, participating in diverse tasks such as grant writing and strategic planning.

The process of engaging in co-design and of documenting practices via technology contributed to the promotoras' expanded sense agency. The participatory design work in which we engaged was premised on the notion that all participants have diverse expertise and that sustainable design requires that the diversity of expertise be leveraged and expanded upon. As participants share equal responsibility for the design and implementation of new infrastructure, their view of their own work within the organization shifts as they take greater responsibility for generating and maintaining designed systems. Enhancing participants' agency through expanded participation is an integral component of social justice work. By shifting the responsibilities within the organization, Impact is closer to meeting its goals of developing community leaders and generating self-sufficient economies.

\section{Discussion}

The promotoras' enhanced ability to generate and pursue professional opportunities was not the result of any one intervention; similarly, it was not the result of their comprehensive collaboration with us, the university researchers. Rather, it is most appropriate to understand it as part of a larger system that was already in motion. Designing a technological tool, alongside conducting ethnographic research and designing workshops, occurred within an existing activity system. Our design was successful because of our ability to recognize, and work with, the momentum of the city, the neighborhood, the non-profit, and the promotoras. 
As we found in our research, ethnographic research prior to design and throughout the design process allows for an understanding of the activity system in which the technology will be used, supporting both equitable and sustainable designs. It is through our ethnography that we were able to echo back what were hearing and support the organization in deciding on the tools that could help them improve their organization. In this sense, the ideas for design came from the community partners and our role as ethnographers and our critical eye towards equity helped shape the collaboration. Our ethnographic work not only gave us an understanding of the organization's and community's activity system, it also provided us with a more national and global context by which to understand Impact's work for food justice. Embedding our design within the existing activity system provided it with the relevance and momentum that supported it in being fully taken up and owned by the users.

Our initial ethnographic research guided our collaborative design work and facilitated our participatory process, allowing us to develop participatory approaches to design so as to attend to both the technical and social infrastructure. This collaborative approach allowed for the consideration of stakeholders' everyday experiences, historical practices, and cultural values. Moreover, the process of engaging the users in the design generated a sense of familiarity with new technology platforms and modeled and encouraged processes of design, analysis, and trouble-shooting, empowering the users to engage with technology in new ways, which has resulted in sustainability.

This case study demonstrates not only the role of ethnography and participatory design in generating equity-oriented design solutions, it also provides a model by which to apply ICTD tenets within the context of the U.S. Notions of development should include marginalized and under-resourced communities within our own nation. Moreover, working within our own nation may support the design and implementation of development projects. In our research, living in the city where we were working provided us with a deep understanding of the non-profit organization and its larger context. This relationship with the physical place where we were researching and designing facilitated the process of generating boundary practices, hybrid research/ practitioner practices (Akkerman \& Bakker, 2011). Generating these hybrid practices, where we leveraged the promotoras' existing practices and extended them via resources and skills available to our research team, was integral to processes of transformation, sustainability, and equity.

Engaging in ICTD in local contexts encourages the sharing of diverse resources, perspectives, and knowledges amongst different subgroups that co-reside within a larger community. It allows for different forms of knowledge to travel across institutions (e.g. from the University context to the non-profit; from the promotoras to the University). In our work, the learning was fluid between participants. Each individual brought a different set of expertise and a different perspective that enriched both our design work and our theoretical understandings. Developing better understandings and networks, sharing resources, and enhancing communication within our local contexts can generate stronger and more equitable societies. 


\section{Conclusion}

As technological innovations are increasingly suggested as a promising solution to generate opportunities for marginalized communities, it is imperative that we look beyond questions of access to critically consider questions of equity. The findings of this article suggest that equitable and empowering technology solutions can be developed via ethnographic research aimed at deeply understanding the focal ecosystem and correspondingly developing responsive and participatory methods that attend to and develop the social infrastructure alongside the technical infrastructure.

\section{References}

Akkerman, S. F., \& Bakker, A. (2011). Boundary crossing and boundary objects. Review of Educational Research, 81(2), 132-169.

Alsop, R., \& Heinsohn, N. (2005). Measuring empowerment in practice: Structuring analysis and framing indicators. Washington, DC: World Bank.

Brunette, W., Sundt, M., Dell, N., Chaudhri, R., Breit, N., \& Borriello, G. (2013). Open Data Kit 2.0: Expanding and refining information services for developing regions. In $A C M$ HotMobile 2013: The 14th Workshop on Mobile Computing Systems and Applications. DOI: $\underline{10.1145 / 2444776.2444790}$

Delgado-Gaitan, C. (2005). Family Narratives in Multiple Literacies. Anthropology \& Education Quarterly. 36(3), 265-272.

Denzin, N.K. (1989). The research act. Englewood Cliffs: Prentice Hall.

Foley, D., \& Valenzuela, A. (2005). Critical Ethnography: The Politics of Collaboration. In The SAGE Handbook of Qualitative Research. Norman K. Denzin and Yvonna S. Lincoln, eds. Pp. 217-234. Thousand Oaks: SAGE Publications.

Friedman, T.L. (2006). The World is Flat: The Globalised World in the Twenty-First Century. London: Penguin.

Gandhia, R., Veeraraghavan, R., Toyama, K., \& Ramprasad, V. (2007). Digital Green: Participatory video for agricultural extension. Information and Communication Technologies and Development, International Conference on ICTD. Bangalore.

Glaser, BG. \& Strauss, AL. (1967). The Discovery of Grounded Theory: Strategies for Qualitative Research. New York: Aldine De Gruyter.

Greenberg, A. (2005). ICTs for Poverty Alleviation: Basic Tool and Enabling Sector. Stockholm: SIDA.

Jurow, A.S., Teeters, L., Shea, M.V., \& Van Steenis, E. (2016) Extending the consequentiality of "invisible work" in the food justice movement, Cognition \& Instruction, 34(3), 210-221. (Special issue edited by M. Bang and S. Vossoughi on participatory design research).

Jurow, A.S., \& Shea, M. (2015). Learning in equity-oriented scale-making projects, The Journal of the Learning Sciences, 00, 1-22.

Kleine, D. (2013). Technologies of Choice? ICTs, development, and the capabilities approach. Cambridge, MA: MIT Press 
Kleine, D. (2012). Signifiers of the life we value? - considering human development, technologies and Fair Trade from the perspective of the capabilities approach. Information Technology for Development. (18)1, 42-60.

Lave, J., \& Wenger, E. (1991). Situated learning: Legitimate peripheral participation. NY: Cambridge University.

mAgri: Mobile for Development, mAgri (2016). Retrieved from http://www.gsma.com/ mobilefordevelopment/programmes/magri/

Palmer, T., \& Pschenichnaya, N. (2015). Tigo Kilimo Impact Evaluation. Groupe Speciale Mobile Association. http://www.gsma.com/mobilefordevelopment/wp-content/uploads/ 2015/09/GSMA_Tigo_Kilimo_IE.pdf Retrieved 1/2016.

Pokharel, P., Gleitsmann, B., Chafik, S., Heberer, C., Ma, M., Tan, C., Yao, Z., Modi, V. (2014) Data-driven Local Planning at National Scale: How data collected on mobile phones enable a Conditional Grants Scheme in Nigeria. Proceedings of the 4th IEEE Global Humanitarian Technology Conference, GHTC 2014, Proceedings of the 4th IEEE Global Humanitarian Technology Conference, GHTC 2014.

Roy, S. (2005). Globalisation, ICT and Developing Nations: Challenges in the Information Age. Thousand Oaks: Sage.

Sachs, J. (2005). The End of Poverty: How we Can Make it Happen in Our Lifetime. London: Penguin Books.

Siraj, S., Shabnam, F., Jalal, A., Zongrone. A., Afsana, K. (2010). "Shasthya Shebika's" role in improving infant and young child feeding practices in rural Bangladesh: BRAC's Experience. Geneva Health Forum.

Strauss, A.L. (1987). Qualitative analysis for social scientists. NY, NY: Cambridge.

Toyama, K. (2010). Can Technology End Poverty. Boston Review. Nov/Dec 2010.

United States Census Bureau. (2014). U.S. Census Data. http://www.census.gov/data/. Retrieved October, 2015.

Viggio, A., Buckner, J.W., \& Dudley, S. (2013). Field Manual: ODK Collect + FormHub for On-Site Data Collection. ICTD Laboratory: ATLAS Institute. Boulder, CO. 